\section{A Life in Training}

\section{J. D. Fletcher}

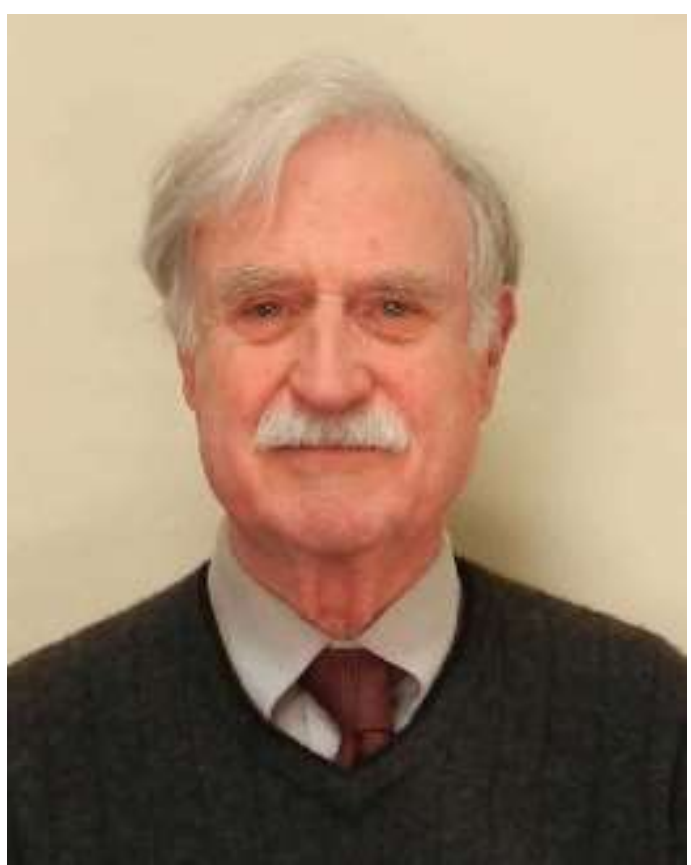

I come from an old New England/New York family that made some money in the early 1800s. They blew whatever was left of it in the 1920s by building a dude ranch in the middle of the Arizona desert. I was raised on the ranch and schooled, grades 2 12 , in Wickenburg (population, 2,500) School District No. 9.

Dude ranching is a tough business. It needs to impress its guests with the joys and experiences of western living, thereby inspiring them to return often with their friends and family members. In our case, it succeeded. My parents, grandfather, and aunt loved all that was needed to sell people on western living. The ranch attracted wellheeled, accomplished individuals and families who shared a fascination with the desert (fortunately, we did not operate in the summer) and cowboy life. My role was to play the horse crazy cowboy kid, something for which I was totally miscast.
The guests included intelligentsia like J. B. Priestly, who wrote about England when he was at the ranch and the desert when he was in England, business executives like Bobby Sears (as in the stores), and movie folks such as Tom Mix (early on) and John Wayne later. Joel McRea and my father became horse riding buddies. Given its clientele, the ranch needed a large collection of good books, many of which I read freely and without guidance. The books ranged from Mein Kampf to The Hobbit to Mickey Spillane mysteries, all of which I read and puzzled over. Confession: I never finished Mein Kampf.

The Wickenburg school system was regularly challenged by students who, in those days, blew in off the desert. They needed and deserved attention. The schools had little time or preparation for my interests. It impressed on me the necessity to individualize instruction beyond what classrooms can provide. I, and some others, found our elementary and secondary education to be unchallenging and irrelevant to our interests. In high school, the game for us was to study no more than the 10 minutes between classes.

I was the class clown and, in high school, the organizer of parties, by virtue of which I was elected to various student leadership positions. With those positions, decent grades, and high College Entrance Examination Board scores, I entered the University of Pennsylvania at age 17 , totally unprepared for serious academics. While there, I had a great time participating in Mask and Wig musicals, playing in bands and in other non-academic activities, about which the less said the better. It was a miracle I lasted two years.

\section{Earlier, I had read Leon Uris' Battle} Cry numerous times and wanted to be a Marine. So, at age 19, and at loose ends, I was inclined to sign up; but when I found that Marine enlistment was four years and the Army's was three, I chose the latter. I enlisted for Airborne service (paratroopers) 
because it was something special—like the Marines. After about eight hours in the Army, I began to understand, fully and forcefully, the benefits of formal academics. Not an uncommon story.

After three years of waiting and some night school at Austin Peay College, I was famished. I enrolled at the University of Arizona, which I could afford to attend (\$200 tuition for Arizonans in those days), and mostly worked my way through devouring whatever learning I could. Because I was over 21, and thereby qualified for a chauffeur's license, I drove buses for the university. After two years and three summer sessions, I graduated with good grades (i.e., high distinction) and in the university's honors program for English. I wanted to bring the joys of literature and the humanities as a professor of English to an engineering school, but while scouting graduate schools I learned of an assistant professor opening in English at the Colorado School of Mines that had attracted over 300 unsuccessful applicants. Uh oh.

On impulse then, I applied to the Educational Psychology program at Stanford (psychology was my minor). By another miracle and high GRE scores, I was not only accepted by the Educational Psychology program but, by an equally amazing stroke of luck, was awarded a research assistantship in the Institute for Mathematical Studies in the Social Sciences, which was led by Pat Suppes, Dick Atkinson, and, at the time, Bill Estes. Dick Atkinson was my advisor. He was a superb writer, researcher, and later Director of NSF, Chancellor of UCSD, and President of the University of California. Pat Suppes was a logician, a wonderful writer who trained his own editors, and an amazing mathematician. He had spent a sabbatical teaching math to second graders, which contributed to his interest in individualized instruction and computer-based techniques for doing so. Later he was awarded the National Medal of Science for his extensive contributions to many areas of science. During my eight years at the Institute, I worked closely and published with both of them. What an honor and what an opportunity to grow! I felt I had come home.

At Stanford, an IBM salesman gave me a set of programmed texts for Fortran II; this was in the winter of 1966-1967. It was love at first statement. I learned Fortran and wrote programs to grind out statistics on a computer-based reading program, which was programmed for an early version of the IBM 1500 system. Classroom teachers were expected to learn, use, and love a macro-based computer language called Coursewriter and use their programs in their courses. We all had much to learn about working with teachers and schools.

A friend whose father helped develop the electron microscope (typical Stanford) suggested I learn Assembler Language for Pine Hall's Digital Equipment Corporation PDP-1D. So I taught myself that and became, okay, good at it. My claim to fame there was to make two (rather than one) drum cylinders available for programs - two thousand 8-bit words for use by a program! Yes, that was a while ago.

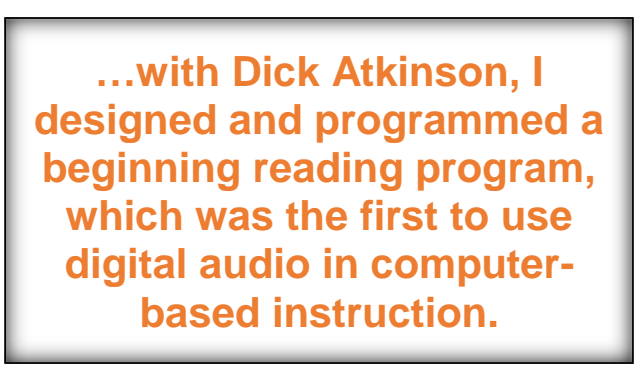

I next taught myself PDP 10 assembler language from its programming manual while we awaited delivery of the computer itself. During that time and with Dick Atkinson, I designed and programmed a beginning reading program, which was the first to use digital audio in computer-based instruction (Fletcher \& Atkinson, 1972). Atkinson still mentions it from time to time. It consisted of 5,000 lines of assembler language code that worked within two hours of loading it into the PDP 10, when I finally got my hands on it. 
What, above all else, I had at Stanford was the freedom to follow learning and lines of research that I loved-18-hour days in the Pine Hall computer lab. I was smitten. Thanks to Professor Raj Reddy in the computer Science Department, I acquired an MS in Computer Science. My math was abominable, but I could program up a storm. That, along with pass/fail opportunities, got me through. And, as intended, I completed a doctorate in Educational Psychology.

Still, I was completely buffaloed by magicians who would visit the Lab in the middle of the night, whip out schematics for the PDP-1, open up the gates (doors to the computers' wiring), and put in cuts and jumpers (adjusting or adding connecting wires) so that the next day we'd have an entirely new machine language instruction to use. Wow. On that basis, I assumed then (early 1970s) that anyone who could earn a living as a programmer had to know electrical engineering, about which I was ignorant. So, after graduation, I sought educational and training psychology positions. If I had stayed with programming, I could have my own vineyard by now. Sic transit Gloria. On the other hand, and based on my familiarity with computers, I have made some contributions to computer uses in education and training that may be worthwhile. Some comments about that follow.

I spent eight years at Stanford as a research assistant and then as a systems programmer. Pat Suppes offered me an opportunity to stay at the Institute, but I had a Mr. Chips fixation and wanted to teach. I turned down Bell Labs, a wonderful opportunity, and accepted a tenure-track position at the University of Illinois, Chicago Circle_-joint appointment in psychology and computer science.

Chicago was and is a great American city, but not for me. I should have known that from my years at Penn. After a year, I turned down offers from Educational Testing Service, another excellent opportunity, as well as from the Defense Advanced Research Program Agency (DARPA). Instead, and thanks to Bill Montague's interest in my work, I headed to the Naval Personnel Research and Development Center (NPRDC) in San Diego. Such was my desire to get back to the West. Also my time in the Army got me interested in military personnel and training matters.

I had seen the computer-based propositional logic course that was developed at Stanford under the direction of Pat Suppes and Adele Goldberg (Goldberg \& Suppes, 1976). It was written in LISP (a still-loved computer language) and delivered, as were all our educational programs, on Model 33 teletypewriters zipping along at 10 characters per second (again, this was late 1960s and early 1970s). In itself, that program was notable, but what especially impressed me was its ability to converse (in tele-typed text) with the learner using the argot of logic generated in real time. Either the machine or the student could ask questions and drive the dialogue. It was far from full natural language understanding, but that didn't matter because the conversation was conducted in the jargon of the subject matter. The machine itself knew the subject matter and was generating the tutoring, in effect "authoring" the instruction, in real time.

To continue, at NPRDC, I found that Dewey Kribs, another early hire, had proposed two technology-based programs for research and development in military training-one focused on videodiscs and one focused on computer-assisted instruction (CAI) using machine intelligence. Dewey successfully proposed these programs (two-page write-ups!) and chose the videodisc program. I chose the Intelligent CAI program.

Thanks to Suppes's Logic program, I had an idea of what needed to be done. Mixed initiative dialogue! Generative CAI based on Artificial Intelligence! Digital Tutoring! I didn't use those terms, which 
came along later, but, based on the Logic Program, that's what I had in mind. Earlier, Wally Feurzeig (on the other coast) had similar thoughts (Feurzeig, 1969). They led him to devise the MENTOR language and program at Bolt Beranek \& Newman in Cambridge, Massachusetts. John Seely Brown (Brown, Burton, \& Zdybel, 1973) at the University of California, Irvine, and a few others were also following that path. The Navy program gave me both the money to advance the technology and the impression (illusion?) that I was doing something useful and worthy. Harry O'Neil, who was a Program Manager at DARPA in 1972, joined in the fray after a year or so and had DARPA chip in more funding for the program, which I continued to manage, as much as anyone manages John Brown.

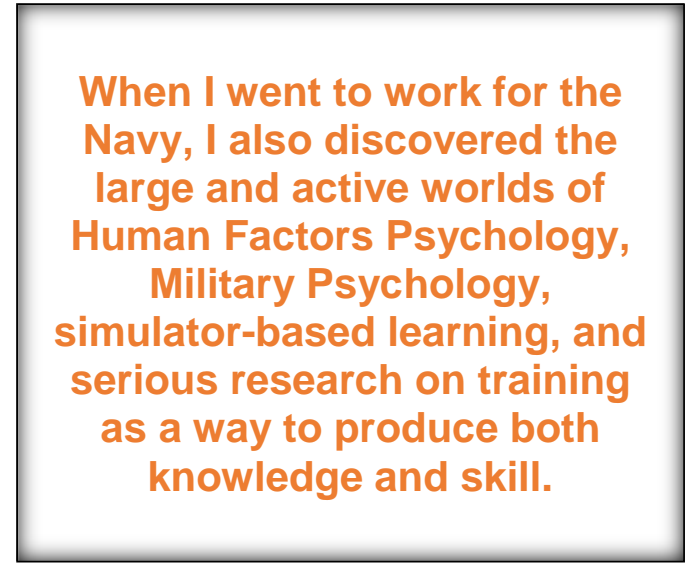

When I went to work for the Navy, I also discovered the large and active worlds of Human Factors Psychology, Military Psychology, simulator-based learning, and serious research on training as a way to produce both knowledge and skill. These were not matters I had stumbled into at Stanford. Also I discovered the world of research program management in the Department of Defense (DoD). What a chance to make a difference! As a program manager (developer, presenter, and funder of ideas), you don't do much hands-on research - well, aside from nudging the work along, assessing its effectiveness, and keeping up with the technology. Nor do you get a lot of credit, notice, or accolades, but it is great for enabling innovation and, okay, enabling others, who are smarter and better prepared, to develop and advance your own and similar ideas.

After about three years at NPRDC, I received a call from Harry O'Neil, whose tour at DARPA was ending. He invited me to apply to for his position. Okay, no one can take Harry's place, but the job was there. Uncharacteristically, I took advantage of a good offer and good luck and accepted it.

In those days, scientists and engineers of all stripes were at DARPA. For instance, Robert Kahn and Vinton Cerf were there managing development of the Internet. All DARPA program managers were (and still are) expected to provide "revolutionary, not evolutionary" ideas, sell them to management, develop them as research programs, and find people who can carry them out. This was DARPA. It was and is a step beyond military Service laboratories like NPRDC. It had more funding and was expected to assume more risk. The results were, and still are, intended to be major breakthroughs, fully supported and expected to produce major advances and capabilities in performing military missions. A later, but equally typical, example is DARPA's development of a device the size of a cigarette pack to replace the racks of computing equipment needed to determine global positioning. DARPA has identified and developed many technologies now commonplace and familiar to us all; the Internet and $21^{\text {st }}$-century global positioning technology are just a couple of examples.

So there I was at DARPA, expected to produce revolutionary advances in human performance for the military. I focused on training, which is important to the military (as well as most other sectors of the national economy), and because, okay, I was an educational psychologist, not a physicist. I brought in Suppes's idea of learning through individualized, computer-generated, tutorial dialogues and the insight that computers could do more than provide drill and practice in subject matter rudiments or 
simply clone text-based programmed learning. I believe drill and practice still has a major role in computers-assisted instruction-introducing the rudiments (e.g., nomenclature, standard procedures, simple concepts) needed for entry into any subject matter. But digital tutoring - an attempt to provide affordable, individualized, one-on-one instruction as dialogue, or a conversation, between the computer and a learner ${ }^{1}$ - is becoming a highly effective technology for getting well beyond rudiments and accelerating the rapid development of expertise and conceptual understanding in a variety of subjects (Kulik \& Fletcher, 2016; Van Lehn, 2011).

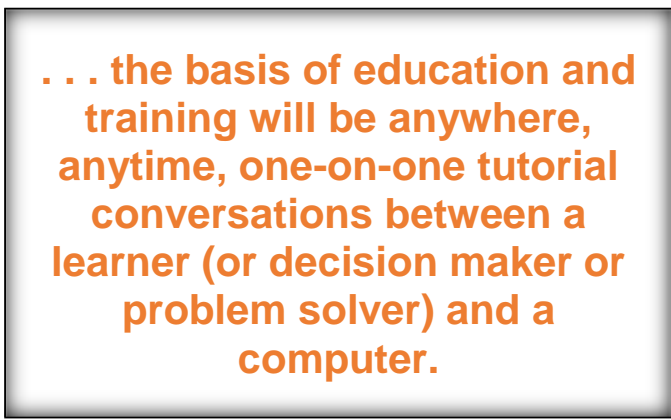

So, based on my experience at Stanford, I pushed the use of computers and digital tutoring in training- the idea being that much of the "authoring" (designing and developing) done by humans in advance could and should be done in real time by computers. At the time and still today, human-based authoring needs to foresee all possible states of the computer and the learner-a challenge that Barr and Feigenbaum (1982) showed to be impossible even for second-grade subtraction. Instead, why not let the computer do much of this work, generatively, and in real time? Identification of many of these states for many learners is helpful for classroom instruction, but something close to $100 \%$ identification is needed for truly individualized instruction.

In 1906, Thorndike (a hard-core behavioral psychologist) observed "The practical consequence of the fact of individual differences is that every general law of teaching has to be applied with

\footnotetext{
${ }^{1}$ Suppes and Morningstar (1969) described this as an Aristotle for every Alexander. We might just suggest a Mark Hopkins for the rest of us.
}

consideration of the particular person ... the responses of children to any stimulus will not be invariable like the responses of atoms of hydrogen or of filings of iron, but will vary with their individual capacities, interests, and previous experience" (p. 83). My idea, then and now, is that reliance on classroom settings to provide instruction will diminish (although for other reasons, schooling in classrooms will remain needed). Instead, the basis of education and training will be anywhere, anytime, one-on-one tutorial conversations between a learner (or decision maker or problem solver) and a computer. The necessary technical and learner information need not be fully preloaded on whatever physical device is presenting the instruction but drawn as needed in real time from external resources, like today's "cloud."

Back to DARPA. The military does a tremendous amount of skill training. I remembered the simulator technology I had seen at NPRDC and elsewhere. In those days, game rooms and gaming devices were all the rage. Notably, people, then as now, were willing to play games for eons, or at least long periods of time, in voluntary learning, even if it was just learning to play the games. Why not create games that people would gladly play and thereby learn skills useful beyond the games? And, instead of just standing alone, why not network them? So in the late 1970s, I developed a DARPA program based on the idea of networked simulation, with a tank gunnery game played by tank commanders and gunners using table-top, computer-driven devices linked and networked with other players engaged in the competition.

We never got to the vision I had in mind because, un-DARPA like, my DARPA 
management insisted on using videodiscs rather than the emerging technology of computer-generated visuals to support the system. That limited the games to prerecorded actions and scenarios, which may have worked to some degree, but not to the extent I had in mind. Be that as it may, my interest in the value of game-based learning continued. Tobias and I pushed for gamebased approaches in a book (2011), but noting that neither of us are gamers, we now tend to leave the field to others.

DARPA Program Managers have a limited time to do whatever they are going to do. When I left DARPA, I recommended they hire Jack Thorpe (Maj, USAF) to fill my position. Jack had already experimented with networking simulators for training in the Air Force. From my networked tank gaming program, Jack then developed something famously called SIMNET (Simulator Networking). SIMNET was based on the idea of global exercises using computer generated visuals (no video discs), but on a much grander scale, i.e, $\$ 300,000$ tank or helicopter simulators rather than my $\$ 20,000$ systems.

The games and exercises were no longer inexpensive, but Jack and General Paul Gorman, among others, made it happen. People sitting in tank simulators in California, who were attacked by people in helicopter simulators in Alabama, could call for assistance from people in jet aircraft simulators in Germany-all networked in real time. Jack's SIMNET effected a massive evolution in computer-based simulation used for training in the military.

After leaving DARPA, I moved to the Army Research Institute for the Behavioral and Social Sciences, where they kindly took me in and tried to figure out what to do with me. They offered me a position as the head of their basic research activities, but I remained focused on applications. I accepted an invitation from the World Institute for Computer Assisted Training (WICAT) in Provo, Utah, which was starting up a non-profit institute and an elementary school to experiment with the practical use of computer-assisted instruction. I was hired as the institute director. However, I found WICAT had more than enough technical talent aboard, and I wanted to get back to more hands-on research, development, and teaching. I moved on to the University of Oregon with a joint appointment in Education and Computer Science, where again I was an odd duck (no allusions intended) and dove back into the Army Research Institute after a couple of years.

Back with the Army, I spent much of my time working with Jesse Orlansky at the Institute for Defense Analyses (IDA). Jesse (another mentor) was one of the early giants of human factors psychology, military training, and military psychology. He could walk unannounced into high-level offices in the Pentagon and be welcomed. He worked for the Science and Technology Division at IDA, which is a Federally Funded Research and Development Center (FFRDC). An FFRDC is a non-profit entity created at the end of World War II to sustain DoD access to the high-level scientific expertise it assembled during that war. FFRDC's opportunities to respond to government requests for proposals are strictly limited so that their research, analyses, and recommendations remain impartial. Jesse offered me a job as a Research Staff Member, which I accepted and where I have remained for more than 30 years.

IDA is assigned to the Office of the Secretary of Defense (OSD) and takes on studies and analyses as required. For instance, if Congress decides that a specific Defense scientific or technical issue, acquisition, or activity deserves OSD attention, OSD, in turn, can easily call on IDA for relevant and impartial analyses, advice, and recommendations. IDA is expected to perform these studies and analyses by applying the most appropriate research technologies and techniques available. It can also provide studies and analyses, beyond OSD and directly for the military Services if OSD approves. 
The work of our small cadre of research psychologists in IDA's Science and Technology Division covers the entire range of personnel, education, and training issues. We need to be quick learners, but it is exciting work. We must keep up with new research results and often help move them from the laboratory to the field. Also, we are free to publish and present our findings, as long as they are not classified.

IDA staff members can also be proactive. If we convince OSD or one of the Services that a particular analysis, assessment, or study is needed, the money and the tasking arrive. The proposal writing experience I acquired at Stanford capabilities was most helpful. For instance, today's Advanced Distributed Learning (ADL) initiative began in the mid-1980s, when a Program Manager in OSD, Gary Boycan, began complaining about the costs to re-program training materials for use in the field (or in the air or at sea) by the active forces and then reprogram it again for use by the Reserves and National Guard. We decided to figure out how to make these materials portable and reusable across different computing platforms, readily available anytime and anywhere.

My idea, thanks to Thorndike (1906), Suppes (1964), and others, continued to be that in the future, training and education would rely on individualized tutorial dialogues generated in real time by computer as described earlier here and later by Fletcher, Tobias, and Wisher (2007). The instruction would be provided anytime, anywhere and presented on something like a portable telephone. As mentioned earlier here, the instructional authoring would be done in real time by the computer. Many of the technical issues needing solutions to

\footnotetext{
2 Today the standards work is vigorously pursued by the Institute for Electrical and Electronics Engineering in cooperation with the
}

achieve the vision were then, as now, being vigorously pursued by intelligent tutoring system researchers. One issue that needed attention was the need for standards to store data so that the computer/instructor could access it from other computer systems and programs as needed. This is not a simple matter particularly because it requires human as well as computer communication and cooperation.

After about a year into this IDA task (sponsored by OSD), we encountered Philip Dodds and brought him aboard. So we had the three of us. Gary Boycan established the necessary OSD program to get it going, I could articulate and defend it with research data and the vision of future education and training described above. Philip knew practically and specifically how to make our vision - to make it all happen. Our plan was to produce specifications or standards based on a Sharable Content Object Reference Model (SCORM) that would be accepted by the people who applied them, as discussed by Dodds \& Fletcher (2004). By the early 2000s, people were saying our vision was not as crazy as it sounded in the 1980s, and, as the OSD Advanced Distributed Learning Initiative, it acquired a Presidential Executive Order along with some steady funding. Coming from IDA, without a particular ax to grind, the idea continues to encourage others, in Defense and elsewhere, to pick up development where IDA, as a studies and analysis shop, must leave off. ${ }^{2}$

Another matter I pursued at IDA is answering the "So what?" question. Training and education tend to be viewed by many in high positions (i.e., in charge of budgets) as expenses rather than investments. I suggest that all of us concerned with advancing new instructional capabilities and practices

Advanced Distributed Learning Initiative (Robson \& Barr, 2018). 


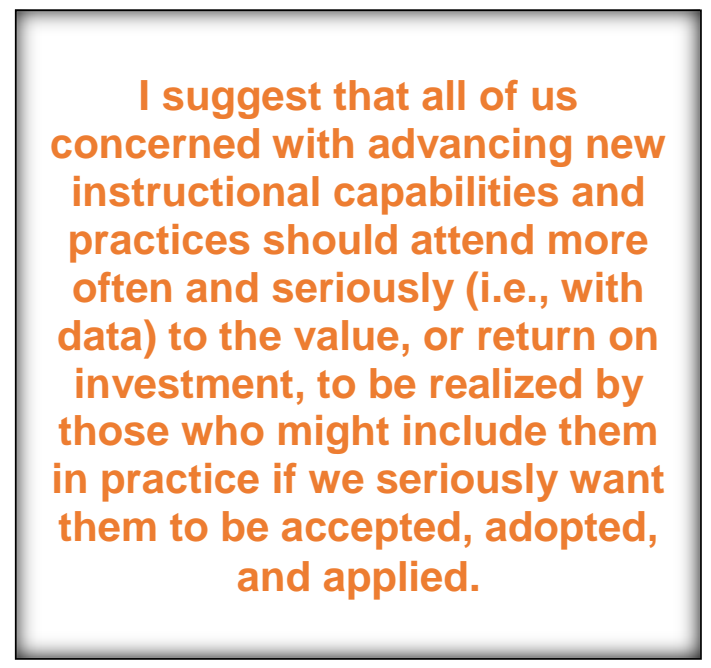

should attend more often and seriously (i.e., with data) to the value, or return on investment, to be realized by those who might include them in practice if we seriously want them to be accepted, adopted, and applied. We must show the "operators" explicitly why they matter. This is a line of work and analysis underway at IDA and elsewhere, but the journey from the laboratory to the field remains difficult and slow.

Changes in education and training are likely to require additional costs. We need to expend more effort to both identify and quantify these costs with sharable models and the return likely to be received from them. For some time, Jesse Orlansky advocated for this work in training (e.g., Orlansky \& Spring, 1979) and Henry Levin has pushed for its application in education (e.g., Levin, 1976). Now, a few others at IDA and I are pursuing standard return on investment models and techniques to assess monetary (does it pay for itself?) and operational (does it increase the likelihood of mission success?) return on investments in education and training.

More could be said, interminably and probably tiresomely, about opportunities and needs shared by training and education to study, analyze, and advise work on simulation and simulators, digital tutoring (aka intelligent tutoring systems), augmented reality, virtual reality, human systems engineering, advanced professional education, and the like. In DoD more attention to these matters is needed by each of the military Services, DoD Dependents' Schools, the War Colleges, NATO, the (international) Technical Cooperation Program, and some activities I cannot discuss here. These matters are not peculiar to military or civilian training. While most of this work was supported, and often conducted, in DoD contexts, much of it could be applied in civilian contexts. Activities and opportunities such as these are rarely discussed in graduate school, but graduate education (and training) prepares us for them. The future is, well, unpredictable, but a good education in learning and instruction helps.

There are many activities and career choices available to educational researchers-well beyond those mentioned in the usual graduate studies track. For those who are ready to perform research, development, and assessments in education and training, there are many opportunities outside of formal academia to contribute to progress and to advance promising ideas in our profession.

Finally, and perhaps to ruffle some feathers, I suggest that we in the business of applying psychology to education and training are closer to engineering than science. I believe our discipline is among the sciences of the artificial (Simon, 1999). Theory is important and helps abstract and bind the findings of research together, but "what works" is paramount in our research. We are charged to devise effective approaches and applications for instruction and learning. In keeping with Simon, if we want a theory for building bridges we should start there, by building many bridges to see which ideas work empirically and which do not, and then follow that up with-not vice versa. We need to focus more than we do on empirical trial and error before leaping to theory. The history of research on mathematical psychology tells us we are not physicists who can do the math and from that devise theory. We must 
begin with more empirical studies to see what works.

If it is not already evident, I particularly want to emphasize research and development opportunities in training, preparing people to perform tasks, jobs, and occupations essential to the military, industry, and the national economy (National Academies of Sciences, Engineering, and Medicine, 2017). A great many people are involved in developing training systems, but they are mostly engineers, human factors psychologists, and industrial psychologists, most of whom must learn about education and training processes and capabilities on the fly. There are many psychologists involved in research and development of training, but I know of few educational psychologists in this work. Training is an area in need of their (our) attention, rife with opportunities for the research, design, development, implementation, and assessment capabilities that we have acquired. More communication and cooperation between educational psychologists and training researchers seems in order. Our prior attempts to facilitate such communication (Tobias \& Fletcher, 2000) did not attract much attention, but continued efforts in that direction seem sorely needed.

Finally, I offer the following nits:

- Good luck happens, don't ignore it. Recognize it for what it is and, if it fits, take advantage of it - a road of travel I should have followed more carefully.

- Even though it is noted by most Acquired Wisdom contributors (Tobias, Fletcher, \& Berliner, 2018), permit me to repeat that mentors and colleagues should be continually sought. Suppes, Atkinson, and Orlansky, among others, were of great value for me. Cronbach and I tried to get together on a number of occasions. I should have pursued that more vigorously. My graduate school friends, colleagues, and members of the Stanford staff contributed immensely to my learning, but there is much to recommend proactive pursuit of mentors and colleagues after and beyond graduate school. Both meanings in the title of this piece apply.

- Further, there is substantial value in communicating and collaborating with colleagues in related and relevant disciplines such as computer science, engineering in general, human factors, economics, statistics (of course), cultural anthropology, linguistics, and the like. This value seems especially evident in practical applications where the issue of what works is paramount, and it may be better accepted outside of university departments where relevance and dedication to a particular discipline may be of more value for advancement than cooperation across discipline boundaries.

- A serious gap remains between research and development and its transition to the field. The path in the military is often for military laboratories to develop an advancement, which is then ignored by the military and left to molder for a number of years until it is discovered by a private contractor who sells the idea to the operational military who then ask why their military labs never produce anything like it.

- Those of us working with research discovery or advancement need to be better prepared to answer the "so what" question about its monetary (does it save money?) and operational (does it increase missions success?) return on investment. This preparation is often neglected or ignored in research circles. 
- Thorndike was right. Individualization in learning remains a critical issue and objective for education and training.

- The world may not be our oyster, but the need to understand and apply emerging instructional capabilities and technologies to, and across, education and training activities continues to escalate and never ends. In an applied world, even more than in the ethereal world of academic theory, anything that works or might work goes.

- There are business aspects to what we do-writing proposals, and managing projects, people, and budgets - and even economic issues such as budgeting and return on investment are well worth attention, study, practice, and learning.

- Learning to write clearly and to the point is critical and never finished. You might expect that from an English major, and some of the above text may demonstrate that it is never perfected. Be that as it may, developing technical writing ability is well worth separate and lifelong study.

\section{References}

Alluisi, E. A. (1991). The development of technology for collective training: SIMNET, a case history. Human Factors, 33, 343-362.

Barr, A., \& Feigenbaum, E. (1982). Buggy. Handbook of artificial intelligence, Vol. 2 (pp. 279-284). Los Altos: William Kaufmann, Inc.

Brown, J. S., Burton, R. R., \& Zdybel, F. (1973). A model-driven question-answering system for mixed initiative computer-assisted construction. IEEE Transactions on Systems, Man, and Cybernetics, SMC-3, 248-257.

Dodds, P. V. W., \& Fletcher, J. D. (2004). Opportunities for new "smart" learning environments enabled by next generation web capabilities. Journal of Education Multimedia and Hypermedia, 13(4), 391-404.

Feurzeig, W. (1969). Computer systems for teaching complex concepts (BBN Report 1742). Cambridge, MA: Bolt, Beranek, \& Newman, Inc. http://www.dtic.mil/dtic/tr/fulltext/u2/684831.pdf

Fletcher, J. D. (2009). Education and training technology in the military. Science, 323, 72-75.

Fletcher, J. D., \& Atkinson, R. C. (1972). An evaluation of the Stanford CAI program in initial reading (Grades K through 3). Journal of Educational Psychology, 63, 597-602.

Fletcher, J. D., Tobias, S., \& Wisher, R. L. (2007). Learning anytime, anywhere: Advanced distributed learning and the changing face of education. Educational Researcher, 36(2), 96102.

Goldberg, A., \& Suppes, P. C. (1976). Computer-assisted instruction in elementary logic at the university level. Educational Studies in Mathematics, 6, 447-474.

Kulik, J. A., \& Fletcher, J. D. (2016). Effectiveness of intelligent tutoring systems: A metaanalytic review. Review of Educational Research, 86, 42-78.

National Academies of Sciences, Engineering, and Medicine. (2017). Building America's Skilled Technical Workforce. Washington, DC: The National Academies Press. https://doi.org/10.17226/23472

Orlansky, J., \& String, J. (1979). Cost-effectiveness of computer-based instruction in military training (Paper P-1375). Alexandria, VA: Institute for Defense Analyses. http://www.dtic.mil/dtic/tr/fulltext/u2/a073400.pdf

Robson, R., \& Barr, A. (2018). Learning Technology Standards - the New Awakening. In R. Sottilare, K. Brawner, A. Sinatra, \& B. Goldberg (Ed.). Proceedings of the Sixth Annual GIFT 
Users Symposium: US Army Research Laboratory. Retrieved from https://www.gifttutoring.org/attachments/download/2712/30_GIFTSym6_AIS\%20Sta ndards_paper_25.pdf

Simon, H. (1999). The sciences of the artificial (3rd ed.). Cambridge MA: MIT Press.

Suppes, P. (1964). Modern learning theory and the elementary-school curriculum. American Educational Research Journal, 1, 79-93.

Suppes, P., \& Morningstar, M. (1969). Computer assisted instruction. Science, 166, 343-350.

Thorndike, E. L. (1906). Principles of Teaching. New York, NY: A. G. Seiler \& Company.

Tobias, S., Fletcher, J. D., \& Berliner, D. C. (2018). Passing the baton to the Second Acquired Wisdom Editorial Team. In S. Tobias, J. D. Fletcher, \& D. C. Berliner (Series Eds.), Acquired Wisdom Series, Vol 1. Education Review, 25. http://dx.doi.org/10.14507/er.v23.2060

Tobias, S., \& Fletcher, J. D. (Eds.) (2000). Training and retraining: A bandbook for business, industry, government, and the military. New York: Macmillan Gale Group.

Tobias, S., \& Fletcher, J. D. (Eds.) (2011). Computer games and instruction. Charlotte, NC: Information Age Publishing. 


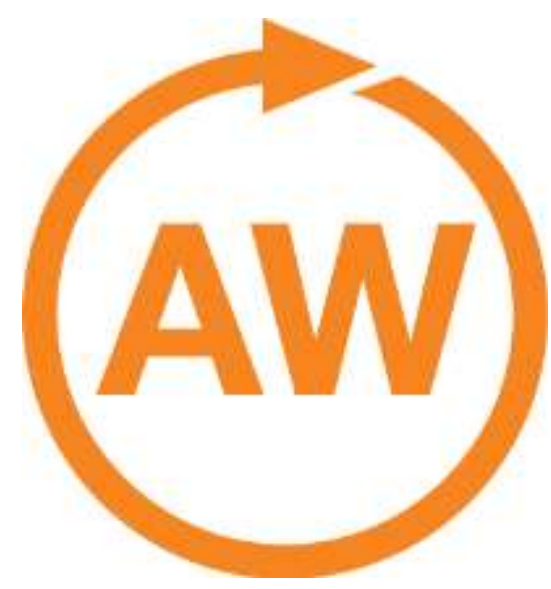

\section{About Acquired Wisdom}

This collection began with an invitation to one of the editors, Sigmund Tobias, from Norman Shapiro a former colleague at the City College of New York (CCNY). Shapiro invited retired CCNY faculty members to prepare manuscripts describing what they learned during their College careers that could be of value to new appointees and former colleagues. It seemed to us that a project describing the experiences of internationally known and distinguished researchers in Educational Psychology and Educational Research would be of benefit to many colleagues, especially younger ones entering those disciplines. We decided to include senior scholars in the fields of adult learning and training because, although often neglected by educational researchers, their work is quite relevant to our fields and graduate students could find productive and gainful positions in that area.
Junior faculty and grad students in Educational Psychology, Educational Research, and related disciplines, could learn much from the experiences of senior researchers. Doctoral students are exposed to courses or seminars about history of the discipline as well as the field's overarching purposes and its important contributors. .

A second audience for this project include the practitioners and researchers in disciplines represented by the chapter authors. This audience could learn from the experiences of eminent researchers-how their experiences shaped their work, and what they see as their major contributionsand readers might relate their own work to that of the scholars. Invitations to potential authors were accompanied by Tobias' chapter in this series for illustrative purposes. Authors were advised that they were free to organize their chapters as they saw fit, provided that their manuscripts contained these elements: 1) their perceived major contributions to the discipline, 2) major lessons learned during their careers, 3) their opinions about the personal and 4) situational factors (institutions and other affiliations, colleagues, advisors, and advisees) that stimulated their significant work.

We hope that the contributions of distinguished researchers receive the wide readership they deserve and serves as a resource to the future practitioners and researchers in these fields. 
education review // reseñas educativas

a multi-lingual journal of book reviews

editors: gustavo e. fischman / melissa cast-brede / gene v glass

Supported by the Mary Lou Fulton Teachers College, Arizona State University

\section{Acquired Wisdom is}

\section{Edited by}

Sigmund Tobias

University at Albany

State University of New York

\section{J. D. Fletcher}

Institute for Defense Analyses

Alexandria VA

\section{David C. Berliner}

Arizona State University

Tempe AZ

\section{Advisory Board Members}

Gustavo Fischman, Arizona State University

Arthur C. Graesser III, Memphis State University

Teresa 1. McCarty, University of California Los Angeles

Kevin Welner, Colorado State University

Education Review/Reseñas Educativas/Resenhas Educativas is supported by the edXchange initiative's Scholarly Communications Group at the Mary Lou Fulton Teachers College, Arizona State University. Copyright is retained by the first or sole author, who grants right of first publication to the Education Review. Readers are free to copy, display, and distribute this article, as long as the work is attributed to the author(s) and Education Review, it is distributed for non-commercial purposes only, and no alteration or transformation is made in the work. More details of this Creative Commons license are available at http://creativecommons.org/licenses/by-nc-sa/3.0/. All other uses must be approved by the author(s) or Education Review. Education Review is published by the Scholarly Communications Group of the Mary Lou Fulton Teachers College, Arizona State University.

Connect with Education Review on Facebook (https://www.facebook.com/pages/EducationReview/178358222192644) and on Twitter@EducReview 